\title{
Study of Phytochemical, Anti-Microbial, Anti-Oxidant, Phytotoxic, and Immunomodulatory Activity Properties of Bauhinia variegata
}

Jaya Bhandari, Pratiksha Thapa, Prasodhan Niraula, Nita Thapa, Nikita Shrestha, Bhupal Govinda Shrestha *

Department of Biotechnology, School of Sciences, Kathmandu University, Nepal

\section{ABSTRACT}

In this paper, we investigated the anti-microbial, anti-oxidant, phytotoxic and immunomodulatory activity of plant Bauhinia variegata and also established the presence of important phytoconstituents which might signify its anticancer property. Phytochemical screening, anti-microbial assay, phytotoxicity assay, anti-oxidant assay and immunomodulatory analysis was done according to the protocol established at Department of Biotechnology, Kathmandu University and Panjwani Center for Molecular Medicine and Drug Research, University of Karachi, Pakistan. In the phytochemical screening, we observed the presence of different phytochemicals like steroids, terpenoids, flavonoids, reducing sugars and glycosides. In case of antimicrobial assay, the plant was found to be most effective against Bacillus cereus with the highest zone of inhibition (ZOI) of $12 \mathrm{~mm}$ and against Rhizopus with ZOI of $11 \mathrm{~mm}$. During the antioxidant assay in comparison to ascorbic acid; at highest concentration, the scavenging activity shown by the plant $B$. variegata are $43.38 \%$ as compared to ascorbic acid $89.25 \%$. In the immunomodulatory assay at the highest concentration i.e. $250 \mu \mathrm{g} / \mathrm{mL}$, the plant showed $75.1 \%$ effect, which showed that the plant has potential anti-inflammatory potential. In phytotoxicity assay, B. variegata showed $20 \%$ phytotoxicity. $B$. variegata has thus been proven to be an important candidate to be used as an antimicrobial, antioxidant, anti-inflammatory, phytotoxic and anticancer agent. Separation of pure compounds with bioassay guided extraction, spectrometric analysis and subsequent cytotoxicity assay of the pure bioactive compounds from $B$. variegate is highly recommended as crude extract itself showed promising phytotoxicity and other pharmaceutical potential.

Keywords: Medicinal plants, phytotoxicity, zone of inhibition, phytochemical screening

\section{INTRODUCTION}

Plants have been the single most productive source of leads for the development of drugs, and over a hundred new products are already in clinical development. Indeed, several scientific studies have described the use of various medicinal plants and their constituents for treatment of diseases. Plants have shown the presence of many valuable compounds, such as lignans, flavonoids, tannins, polyphenols, triterpenes, sterols, and alkaloids, that show a wide spectrum of pharmacological activities, including anti-inflammatory, anti-amyloidogenic, anti-cholinesterase, hypolipidemic, and antioxidant effects [1]. Considerable research on pharmacognosy, phytochemistry, pharmacology and clinical

${ }^{*}$ Corresponding author:

Bhupal Govinda Shrestha

Department of Biotechnology, School of Sciences,

Kathmandu University

Dhulikhel 45200, P.O.Box- 6250 Kathmandu, Nepal

E-mail: bgs@ku.edu.np therapeutics has been carried out on ayurvedic medicinal plants. Natural products, including plants, animals and minerals have been the basis of treatment of human diseases [2]. Many complementary and alternatives medicines are offered to patients with cancer. Among them, herbal medicines have a substantial place. These plants are mainly used to reduce adverse effects of anticancer treatments and for specific anticancer properties [3]. Plant extracts are kinds of important anticancer drugs. Anticancer drugs research has focused on several important plant extracts such as resveratrol, ricin, epigallocatechin-3-gallate, oridonin, juglone, quercetin, matrine, nordihydroguaiaretic acid.

In vitro and in vivo studies have shown that the an-

\section{How to cite:}

Bhandari J, Shrestha BG (2017) Study of Phytochemical, AntiMicrobial, Anti-Oxidant, Phytotoxic, and Immunomodulatory Properties of Bauhinia variegata. J. Trop. Life. Science 7 (1): $83-90$. 
titumor mechanism of plant extract includes induction of apoptosis, cytotoxicity, redifferentiation, anti-angiogenesis, anti-invasion and anti-metastasis. Plant extracts have characteristics of multi-link and multi-target. Part of plant extracts have been used in preclinical studies. In-depth study of the anti-tumor mechanisms of plant extracts on cancer treatment is important, and the full mechanism needs further study [4]. A huge reservoir of bioactive compounds exists in many species of plants of Earth, only a small percentage of which have been examined and continued to be an important source of anticancer agents. Worldwide efforts are ongoing to identify new anticancer compounds from plants. With the current decline in the number of new molecular entities from the pharmaceutical industry, novel anticancer agents are being sought from traditional medicines [5]. A number of undesired side effects sometimes occur during chemotherapy. Natural therapies, such as the use of plant-derived products in cancer treatment, may reduce adverse side effects. Currently, few plant products are being used to treat cancer. However, a myriad of many plant products exist that have shown very promising anti-cancer properties in vitro, but have yet to be evaluated in humans [6]. For over 40 years, natural products have served us well in combating cancer. The main sources of these successful compounds are plants from the terrestrial and marine environments. Another major contribution comes from plant alkaloids. A vast array of metabolites can be obtained from the marine world, which can be used for effective cancer treatment. The search for novel drugs is still a priority goal for cancer therapy, due to the rapid development of resistance to chemotherapeutic drugs. In addition, the high toxicity usually associated with some cancer chemotherapy drugs and their undesirable side-effects increase the demand for novel anti-tumour drugs active against untreatable tumours, with fewer side-effects and/or with greater therapeutic efficiency [7]. Studies on a wide spectrum of plant secondary metabolites extractable as natural products from fruits, vegetables, teas, spices, and traditional medicinal herbs, show that these plant natural products can act as potent anti-inflammatory, antioxidant or anticancer agents. The recent advances in genomics, proteomics and metabolomics have enabled biologists to better investigate the potential use of immunomodulatory natural products for treatment or control of various cancerous diseases. The cancer preventive or protective activities of the various immunomodulatory natural products lie in their effects on cellular levels in- cluding detoxifying and antioxidant enzyme systems, and the induction of anti-inflammatory and antitumor or anti-metastasis responses, often by targeting specific key transcription factors like nuclear factor kappa B (NF-kB), activator protein (AP-1), signal transducers and activators of transcription (STAT) and other proteins [8]. Natural products have been the biggest single source of anticancer drugs and there are continued efforts to explore the bioactive chemicals. Diversity provided by nature in order to find new lead compounds, bioassay test methods have developed into high throughput screening assays using both cell-based and molecular approaches [9].

This few inventions related to a novel anticancer poly-herbal composition comprises of stem bark of Bauhinia variegata, Oroxylum indicum, Tecomella undulata and leaves of Indigofera tinctoria. Few novel composition found in plants are useful in the condition of cancer, immunosuppression, uncontrolled proliferation and angiogenesis $[10,11,12]$. Highest antioxidant potential was found in stem bark extracts of $B$. variegata $[13,14,15]$. Studies showed significant antioxidant activities of these $B$. variegata and suggested that it showed pronounced cytotoxic effect against DU-145, HOP-62, IGR-OV-1, MCF-7, and THP-1 human cancer cell lines with 90-99\% cell growth inhibitory activity. Ethyl-acetate fraction of the plant also produced considerable cytotoxicity against MCF-7 and THP-1cell lines $[16,17,18,19,20,21,22]$. Studies of ethanolic extracts of plant material showed the presence of carbohydrate, protein, glycosides, triterpenoids, saponins and steroids [23, 24]. Extracts of B.variegata have antitumor, antimicrobial, antigoitrogenic, hepatoprotective and hemagglutination properties [25]. Few studies have revealed the chemopreventive role of variegata flower extracts against 7, 12-Dimethylbena[a] anthracene (DMBA) induced skin carcinogenesis in mice [26]. In a search for novel anticancer compounds From medicinal plants, the isolated flavanone from Bauhinia was tested for cytotoxic activity against 57 human tumor lines, representing leukemia, non-small cell lung, colon, central nervous system, melanoma, ovarian, renal, prostate and breast cancers and were found effective against most of them [27]. The inhibitory effect of bauhinione on K562 cells was correlated with its inhibition and apoptosis induction in G2-M phase [28]. A novel flavonolglycoside 5,7,3',4'-tetrahydroxy-3-methoxy-7-Oa-L-rhamnopyranosyl(1®3)-O-b-D-galactopyranosidefrom the roots of $B$. variegata showed anti-inflammatory activity [29]. Similar research has been reported for 
Withania somnifera [30, 31].

\section{MATERIALS AND METHODS Collection of plant materials}

$B$. variegata whole plants were collected from $\mathrm{Pa}$ nauti area of Kavre district, Nepal. The whole plant were then dried in shade, left over for 15 days and macerated and powdered with the help of kitchen grinder.

\section{Preparation of plant extracts}

The dry powder of $B$. variegata (100 g) was dipped in $80 \%$ aq. ethanol for three days stirring twice a day [32]. The solution at the end of third day was filtered and then concentrated in high vacuum-rotator evaporator and finally all the solvent was evaporated using freeze dryer to get the semi-solid plant extract. The same procedure was repeated three times and the freeze-dried extract was collected together. The yield of the plant powder B. variegata in aq. ethanol weighed after the freeze drying was $12.07 \mathrm{~g}$. The extract was then kept in glass vial with airtight caps and stored at $4^{\circ} \mathrm{C}$.

\section{Phytochemical screening}

Phytochemical screening was done using the methods as described [32].

1. Test for Alkaloids: $5 \mathrm{~mL}$ of extract was concentrated to yield a residue. Residue was dissolved in $3 \mathrm{~mL}$ of $2 \%(\mathrm{v} / \mathrm{v}) \mathrm{HCl}$, few drops of Mayer's reagent was added. Appearance of the dull white precipitate indicated the presence of basic alkaloids.

2. Test for Coumarin: $4 \mathrm{~mL}$ extract solution was taken; 1-2 drops of water (hot) was added. Volume was made half (UV fluorescence). $10 \% \mathrm{NH}_{4} \mathrm{OH}$ was added to another half volume (strong fluorescence). Presence of green fluorescence indicated the presence of Coumarin.

3. Test for Saponins: $2 \mathrm{~mL}$ extract was shaken vigorously for 30 seconds in a test tube. Persistence of thick forth even after 30 minutes indicated the presence of saponins.

4. Test for Glycosides: $2 \mathrm{~mL}$ of extract was dried till 1 $\mathrm{mL}$. As much as $1-2 \mathrm{~mL} \mathrm{NH_{4 }} \mathrm{OH}$ was added and shaken. Appearance of cherish red colour indicated the presence of glycosides.

5. Test for Reducing Sugars: $0.5 \mathrm{~mL}$ of extract was taken and $1 \mathrm{ml}$ distilled water was added. About 5-8 drops of Fehling's solution (hot) was added. Presence of brick red precipitation indicated the presence of reducing sugar.
6. Test for steroids: $1 \mathrm{~mL}$ extract was dissolved in 10 $\mathrm{mL}$ chloroform. Equal volume of conc. $\mathrm{H}_{2} \mathrm{SO}_{4}$ was added by the side of test tube. Upper layer turned red and sulphuric acid layer turned yellow with green fluorescence. This indicated the presence of steroids.

7. Test for Quinone: $1 \mathrm{~mL}$ of extract was taken. As much as $1 \mathrm{~mL}$ of conc. $\mathrm{H}_{2} \mathrm{SO}_{4}$ was added. Formation of red colour indicated the presence of quinone.

8. Test for Terpenoids: $5 \mathrm{~mL}$ of extract was taken and mixed with $2 \mathrm{~mL}$ of chloroform. As much as $3 \mathrm{~mL}$ of conc. $\mathrm{H}_{2} \mathrm{SO}_{4}$ was added to form a layer. Reddish brown precipitate formation at the interface formed indicated the presence of terpenoids.

\section{2, 2-diphenyl-1-picrylhydrazyl radical (DPPH) free radi- cal scavenging assay}

2, 2-diphenyl-1-picrylhydrazyl radical (DPPH) is a dark-coloured crystalline powder composed of stable free-radical molecules. DPPH has major application in laboratory research most notably in antioxidant assays. DPPH solution ( $95 \mu \mathrm{L}, 300 \mu \mathrm{M})$ in Ethanol was mixed with test solution $(5 \mu \mathrm{L}, 500 \mu \mathrm{M})$. The reaction was allowed to progress for $30 \mathrm{~min}$ at $37^{\circ} \mathrm{C}$ and absorbance was monitored by microplate reader, SpectraMax340 at $517 \mathrm{~nm}$. Upon reduction, the colour of the solution fades (violet to pale yellow). Percent Radical Scavenging Activity (\% RSA) was determined by comparison with a Dimethyl sulfoxide (DMSO) containing control. The concentration that causes a decrease in the initial DPPH concentration by $50 \%$ is defined as IC- 50 value. The IC-50 values of compounds were calculated by using the EZ-Fit Enzyme kinetics software program (Perrella Scientific Inc. Amherst, MA, USA). N-acetylcysteine and ascorbic acid are used as the reference compounds [32].

\section{Agar plate diffusion method for antimicrobial activity}

Medium was dissolved and autoclaved at $121^{\circ} \mathrm{C}$ for 15 minutes, cooled up to $45^{\circ} \mathrm{C}$ and then $40-50 \mathrm{~mL}$ media was poured in sterile $14 \mathrm{~cm}$ diameter petri plate, and then allowed to solidify and kept at room temperature. Preparation of plant extract: Stock solution of $400 \mathrm{mg} / \mathrm{mL}$ was prepared by weighing $200 \mathrm{mg}$ of plant extract in $1.5 \mathrm{~mL}$ eppendorf tube and the final volume of $0.5 \mathrm{ml}$ of DMSO was added by micropipette. Extract was completely dissolved by vortexing for 5-10 minutes. Test solution of $200 \mathrm{mg} / \mathrm{mL}, 100 \mathrm{mg} / \mathrm{mL}, 50$ $\mathrm{mg} / \mathrm{mL}$, and $25 \mathrm{mg} / \mathrm{mL}$ concentrations was prepared.

Preparation of inoculums: Each culture to be tested 
was streaked onto nutrient agar to obtain isolated colonies. Overnight incubation was done at $37^{\circ} \mathrm{C}$. Then isolated colonies were transferred by the help of sterile loop onto Muller Hinton Broth. Overnight incubation was done at rotary shaker at $37^{\circ} \mathrm{C}$.

Inoculation: For inoculation, swabbing was done with the help of cotton. Sterilized filter paper discs were dipped into the desirable concentration of the plant extracts then applied to the plates; incubated at $37^{\circ} \mathrm{C}$ for 24 hours. After incubation, the diameter of the Zone of inhibition was measured.

\section{Phytotoxicity or Lemna bioassay for inhibitors and pro- moters of plant growth}

The members of Lemnaceae family are suitable organisms to investigate physiological processes. It is a quick measure of phytotoxicity of the materials. The Lemna minor phytotoxicity assay is a useful primary screen for weedicides search. It is also observed that natural antitumor compounds can inhibit the lemna growth.

E-Medium is prepared by mixing its constituents in $1000 \mathrm{~mL}$ distilled water and $\mathrm{pH}$ is adjusted between 6.0 and 7.0 by adding $\mathrm{KOH}$ pellets (Stock solution). Working E-medium is prepared by mixing $100 \mathrm{ml}$ of stock solution and $900 \mathrm{~mL}$ of distilled water. $30 \mathrm{mg}$ for crude extract/ compound is dissolved in $1.5 \mathrm{~mL}$ of solvent (Methanol/ Ethanol etc.) serving as stock solution. Three flasks are inoculated with 10,100 and $1000 \mu \mathrm{L}$ of solution pipette from the stock solution for 10, 100 and $1000 \mu \mathrm{g} / \mathrm{mL}$. The solvent was allowed to evaporate overnight. Add $20 \mathrm{~mL}$ of working E. medium and then plant of Lemna minor, each containing a rosette of two to three fronds, to each flask (total 20 fronds). Other flasks supplemented with E-medium and reference (standard drug) plant growth inhibitors and promoters serve as negative and positive controls, respectively. Place the flaks in growth cabinet for seven days. Plants should be examined daily during incubation. Count and record number of fronds per flasks on day 7 . Results are analyzed as growth regulation in \% age, calculated with reference to the negative control by this formula.

$\%$ regulation $=\left(100-\left(\frac{\text { Number of fronds in test }}{\text { Number of fronds in negative control }}\right)\right) \times 100$

\section{Immunomodulatory assay (for anti-inflammatory po- tential)}

Immunomodulation is the regulation and modulation of immunity either by enhancing or by reducing the immune response whereas an immunomodulator
Table 1. Results of phytochemical screening of $B$. variegata

\begin{tabular}{cc}
\hline Phytochemicals & B. variegata \\
\hline Alkaloids & Available \\
Tannins & Available \\
Reducing sugar & Available \\
Coumarin & Available \\
Glycosides & Available \\
Quinone & Not-available \\
Steroids & Not-available \\
Terpenoids & Available \\
Saponin & Available \\
Flavonoids & Available \\
\hline
\end{tabular}

may be defined as a biological or synthetic substance, which can stimulate, suppress or modulate any of the components of the immune system including both innate and adaptive arms of the immune responses.

Medicinal plants are a rich source of immunomodulators. Since the drugs available in the market have adverse side effects, the use of natural products as an alternative method for treatment has been on the rise in the last few decades. A large number of plants like Actinidia, Aesculus, Allium, Aloevera, Asparagus, Centella, Emblica, Magnifera, Withania, Piper and Tinosporaetc possess potent immunomodulatory activity.

Luminol-enhanced chemiluminescence assay was performed, as described by Helfand [33]. Briefly $25 \mu \mathrm{l}$ of diluted whole blood HBSS++ (Hanks Balanced Salt Solution, containing Calcium Chloride and Magnesium Chloride) [Sigma, St. Louis, USA] was incubated with $25 \mu \mathrm{L}$ of three different concentrations of compounds $(1,10$ and $100 \mu \mathrm{g} / \mathrm{ml})$, each in triplicate. Control wells received $\mathrm{HBSS}_{++}$and cells, but no compounds. Test was performed in white half area 96 well plates [Costar, NY, USA], which was incubated at $37^{\circ} \mathrm{C}$ for 15 minutes in the thermostat chamber of luminometer [Labsystems, Helsinki, Finland]. After incubation, $25 \mu \mathrm{l}$ of serum opsonized zymosan (SOZ) [Fluka, Buchs, Switzerland] and $25 \mu \mathrm{L}$ of intracellular reactive oxygen species (ROS) detecting probe, luminol [Research Organics, Cleveland, OH, USA] were added into each well, except blank wells (containing only $\mathrm{HBSS}_{++}$). The level of the ROS was recorded in luminometer in term of relative light units (RLU). Standard used for the assay is Ibuprofen (IC-50 = $11.2 \pm 1.9$ ).

\section{RESULTS AND DISCUSSION}

In the phytochemical screening, as shown in Table 1 , we observed the presence of different phytochemic 


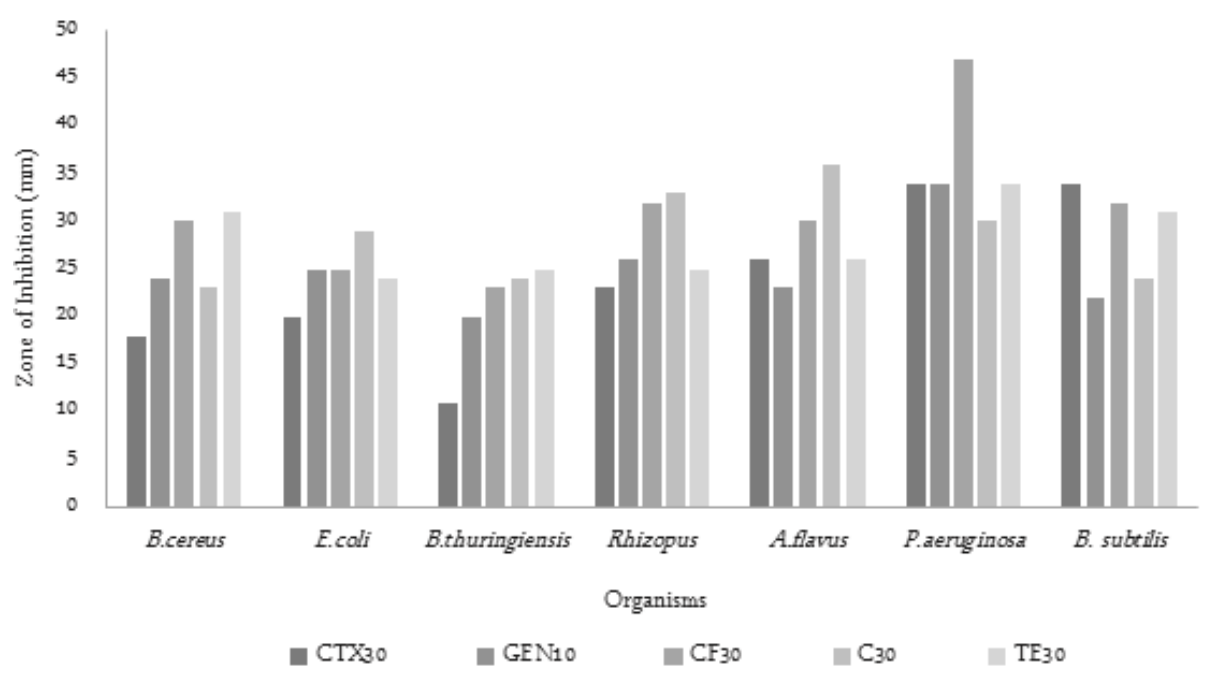

Figure 1. Zone of inhibition of standard antibiotics

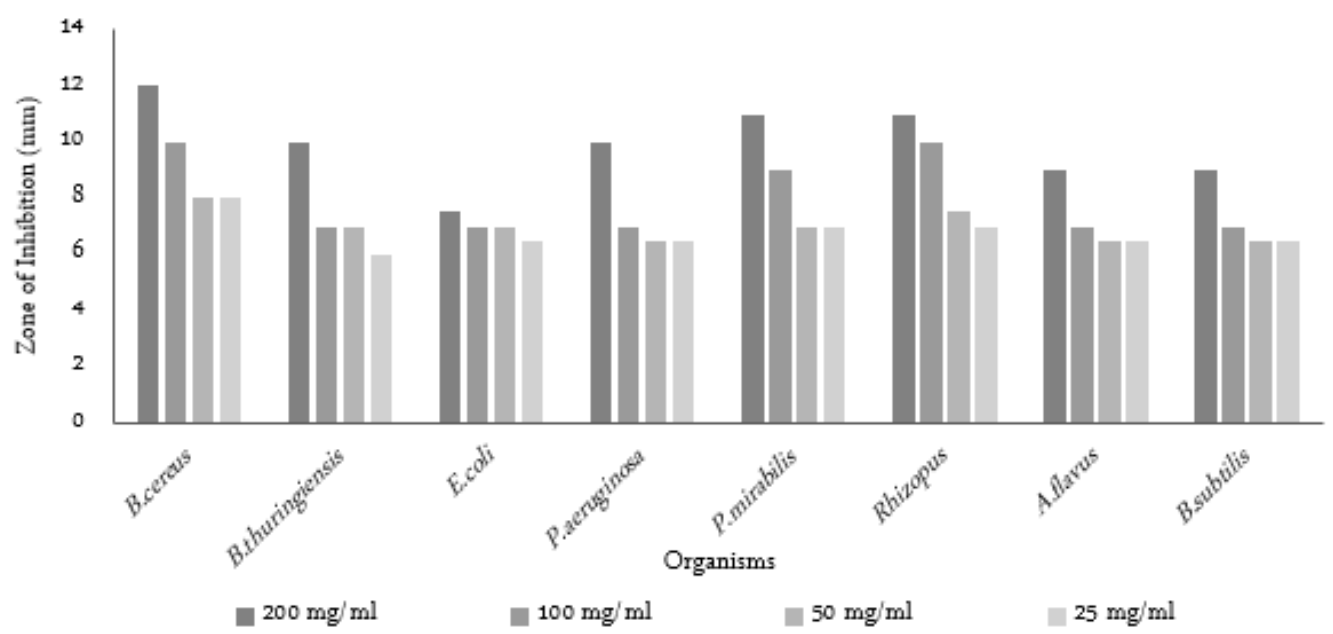

Figure 2. Antimicrobial assay of $B$. variegata

als like alkaloids, tannins, reducing sugar, coumarin, glycosides, terpenoids, saponins and flavonoids.

Antimicrobial assay was performed with the plant extract of $B$. variegata by agar plate diffusion method. Five different antibiotics were used as standard drugs (Figure 1).

In the phytochemical screening, as shown in Table 1 , we observed the presence of different phytochemicals like alkaloids, tannins, reducing sugar, coumarin, glycosides, terpenoids, saponins and flavonoids.

Antimicrobial assay was performed with the plant extract of $B$. variegata by agar plate diffusion method. Five different antibiotics were used as standard drugs.

\section{Results of antimicrobial assay}

In case of antimicrobial assay Figure $2, B$. variegata showed ZOI, of $12 \mathrm{~mm}, 10 \mathrm{~mm}, 8 \mathrm{~mm}$ and $8 \mathrm{~mm}$ against Bacillus cereus at the concentration gradient of $200 \mu \mathrm{g} / \mathrm{mL}, 100 \mu \mathrm{g} / \mathrm{mL}, 50 \mu \mathrm{g} / \mathrm{mL}$ and $25 \mu \mathrm{g} / \mathrm{mL}$ re- spectively. Against Bacillus thuringiensis it was $10 \mathrm{~mm}$, $7 \mathrm{~mm}, 7 \mathrm{~mm}$ and $6 \mathrm{~mm}$; against Escherichia coli it was $7.5 \mathrm{~mm}, 7 \mathrm{~mm}, 7 \mathrm{~mm}$ and $6.5 \mathrm{~mm}$; against Pseudomonas aeruginosa it was $10 \mathrm{~mm}, 7 \mathrm{~mm}, 6.5 \mathrm{~mm}$ and 6.5 $\mathrm{mm}$; against Pseudomonas mirabilis it was $11 \mathrm{~mm}, 9$ $\mathrm{mm}, 7 \mathrm{~mm}$ and $7 \mathrm{~mm}$; against Rhizopus it was $11 \mathrm{~mm}$, $10 \mathrm{~mm}, 7.5 \mathrm{~mm}$ and $7 \mathrm{~mm}$; against Aspergillus flavus it was $9 \mathrm{~mm}, 7 \mathrm{~mm}, 6.5 \mathrm{~mm}$ and $6.5 \mathrm{~mm}$ and against B. subtillis it was $9 \mathrm{~mm}, 7 \mathrm{~mm}, 6.5 \mathrm{~mm}$ and $6.5 \mathrm{~mm}$; respectively at the above mentioned concentration gradient.

\section{Results of antioxidant assay}

During the antioxidant assay Figure 3, in comparison to Ascorbic acid at $1 \mu \mathrm{g} / \mathrm{mL}, 2 \mu \mathrm{g} / \mathrm{mL}, 3 \mu \mathrm{g} / \mathrm{mL}, 4$ $\mu \mathrm{g} / \mathrm{mL}, 5 \mu \mathrm{g} / \mathrm{mL}$ and $10 \mu \mathrm{g} / \mathrm{mL}$, the scavenging activity shown by the plant $B$. variegata was $11.16 \%, 16.3 \%$, $19.6 \%, 21.9 \%, 34.12 \%$ and $43.38 \%$ respectively and by 


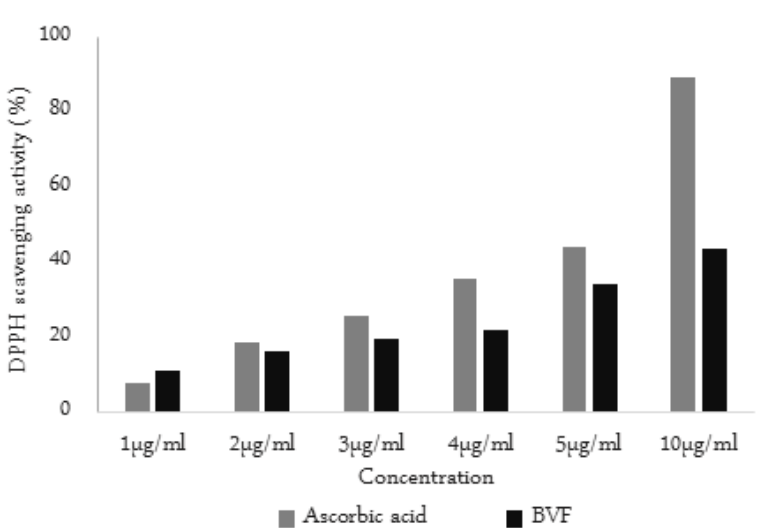

Figure 3. Results of antioxidant assay of $B$. variegata

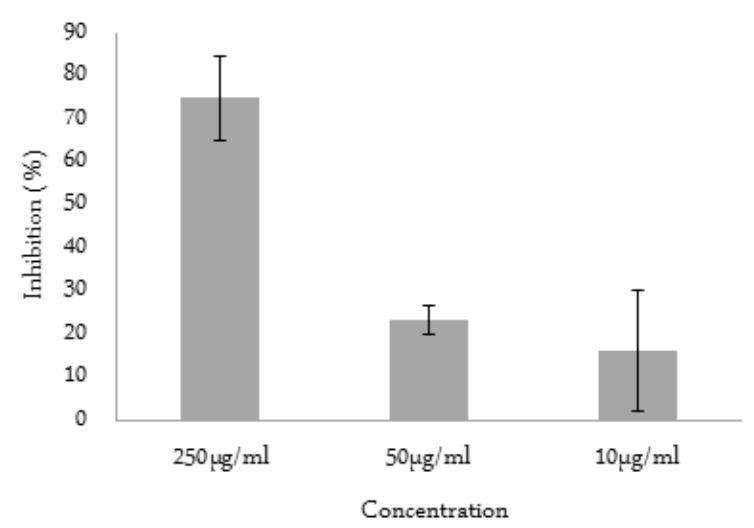

Figure 4. Immunomodulatory assay of $B$. variegata

ascorbic acid it was $8.07 \%, 18.45 \%, 25.81 \%, 35.46 \%$, $44.25 \%$ and $89.25 \%$ respectively, in the same concentration gradient.

\section{Results of immunomodulatory assay}

In the immunomodulatory assay Figure 4, anti-inflammatory assay, at $250 \mu \mathrm{g} / \mathrm{mL}, 50 \mu \mathrm{g} / \mathrm{mL}$ and 10 $\mu \mathrm{g} / \mathrm{mL}$ the average immunomodulatory effect are $75.1 \%, 23.6 \%$ and $16.4 \%$.

\section{Result of phytotoxicity assay}

In phytotoxicity assay, at $1000 \mu \mathrm{g} / \mathrm{mL}, 100 \mu \mathrm{g} / \mathrm{mL}$ and $10 \mu \mathrm{g} / \mathrm{mL}$ the plant B. variegata showed $20 \%, 20 \%$ and $5 \%$ phytotoxicity.

Some of the reported cytotoxicity of different plant sample can be attributed to the synergic effect of all secondary metabolites that could have been present in the plants. The phytoconstituents like alkaloids, terpenoids and phenols can be attributed for the marked cytotoxicity.

The prevalence of differential anti-oxidant potential may be ascribed to their different phenolic content group and flavonoids compounds. The extract with raised phenolic content may have contributed to the higher anti-oxidant activity. Based on the results obtained, it can be concluded that the plant contains essential phyto-constituents and possess potent anti-bacterial, anti-oxidant, phytotoxic, immunomodulatory and anti-cancer features, as has been reported earlier for Berberis aristata [34]. Further investigations on the isolation of the active component of the extract will throw more information on the mechanism of action.

Phenolics and flavonoids from the plants are found to possess potent antioxidants and homeostatic balance between anti-oxidant and pro-oxidant which are reported to be significant for physiological functioning as well as precluding different degenerative debilities. Conclusively, results of our study embodies the fact that the extracts are an eminent source of natural antioxidants with consequential potential in reducing the oxidative stress and preventing degenerative ailments and also cancer. Bioactivity guided purification and extraction of the pure compounds may lead to increased activity of the compounds [34].

The degree of variability in antimicrobial potential could be linked to the varying presence of different phytochemicals like flavonoids and phenols having antioxidant potential and play an important role in protection against oxidative stress. These phytochemicals exhibit restriction of generation of free radicals which damages target biomolecules. The variability in different phytochemicals contents across populations may be attributed to morphological as well as biochemical characters of the plants. This would, however, suggest source specific variation of antioxidant efficacies. The phytoconstituents like alkaloids, terpenoids and phenols can be attributed for cytotoxicity. The presence of flavonoids, and saponins in isolation or in synergy in these crude extracts used in the study might also be responsible for exhibiting anticancer efficacies. There are testaments signifying biological interactions of flavonoids, polyphenols, or phenolic compounds [35].

Figure 1, 2, 3, and 4 .

\section{CONCLUSION}

$B$. variegata has thus been proven to be an important candidate to be used as an anti-microbial, anti-oxidant, anti-inflammatory, phytotoxic and anticancer agent. Separation of pure compounds with bioassay guided extraction, spectrometric analysis and subsequent cytotoxicity assay of the pure bioactive compounds from $B$. variegata is highly recommended as crude extract itself showed promising cytotoxicity. 


\section{ACKNOWLEDGMENT}

\section{REFERENCES}

1. Rao R, Descamps O, Varghese J et al. (2012) Ayurvedic medicinal plants for Alzheimer's disease: A review. Alzheimer's Research and Therapy 4 (3): 22.

2. Balakrishna R, Patel B, Jagir R, Prabhakaran V (2011) Cassia auriculata - a phytopharmacological review. Journal of Advances in Drug Research 1 (2): 46-57.

3. Huet M (2013) Medicinal plants in cancer patients: current practices and evaluation. Bulletin du cancer 100 (5): 485-495.

4. Zhang J, Chen C, Ze-zhang T (2012) Anti-cancer research progress of plant extract. Guoji Zhongliuxue Zazhi 39 (8): 579-584. doi:10.3760/cma.j.issn.1673-422X.2012.08.006.

5. Dhanamani M, Lakshmi D, Kannan, S (2011) Ethno medicinal plants for cancer therapy - A review. Hygeia 3 (1): 1-10.

6. Desai G, Qazi GN, Ganju RK et al (2008) Medicinal plants and cancer chemoprevention. Current Drug Metabolism 9 (7): 581-591. doi:10.2174/138920008785821657.

7. Demain A, Vaishnav L (2011) Natural products for cancer chemotherapy. Microbial Biotechnology 4 (6): 687-699. doi:10.1111/j.1751-7915.2010.00221.x

8. Aravindaram K, Yang N (2010) Anti-inflammatory plant natural products for cancer therapy. Planta Medica 76 (11): 1103-1117. doi:10.1055/s-0030-1249859

9. Harvey A, Cree Ian A (2010) High-throughput screening of natural products for cancer therapy. Planta Medica 76 (11): 1080-1086. doi:10.1055/s-0030-1250162

10. Gunalan G, Saraswathy A, Vijayalakshmi K (2012) HPTLC fingerprint profile of Bauhinia variegata Linn. Leaves. Asian Pacific Journal of Tropical Disease 2: 21-25

11. Gokani R, Rachchh M, Savjiyani J (2014) Novel anticancer herbal composition, method of preparation of the same and use thereof. Indian Pat. Appl.

12. Uddin G, Sattar S, Rauf, A (2012) Preliminary phytochemical, in vitro pharmacological study of Bauhinia alba and Bauhinia variegata flowers. Middle-East Journal of Medicinal Plants Research. 1(4): 75-79.

13. Anwar A, Shumaila P (2013) Microwave-assisted extraction and nitric oxide and superoxide attenuation potential of polyphenolics from Bauhinia variegate. Asian Journal of Chemistry 25: 13.

14. Klafke G, Borsuk S, Gonçales R, Arruda F et al. (2013) Inhibition of initial adhesion of oral bacteria through a lectin from Bauhinia variegata L. var. variegata expressed in Escherichia coli. Journal of Applied Microbiology 115: 1222-1230

15. Klafke G, Borsuk S, Gonçales R et al. (2013) Inhibition of initial adhesion of oral bacteria through a lectin from Bauhinia variegata L. var. variegata expressed in Escherichia coli. Journal of Applied Microbiology 115: 12221230.

16. Mishra A, Sharma A, Kumar S et al. (2013) Bauhinia variegata leaf extracts exhibit considerable antibacterial, antioxidant, and anticancer activities. BioMed Research International 7: 1-10.

17. Negi A, Sharma N, Pant R et al (2012). Determination of total phenolic content of the stem bark of Bauhinia variegata Linn: an approach to standarization. Pharma Research 7 (2): 16-22.

18. Verma R, Awasthi M (2013) Effect of salt treatment on phenolic compounds of Bauhinia variegata (Kachnar) and Cordia dichotoma (Lesora). Advances in Food Sciences 35 (1): 37-39.

19. Dhaka D, Punia A (2012) Antimicrobial, phytochemical and antioxidant assay of Bauhinia variegata (Kachnaar) extracts against somepathogenic microbes. Research Journal of BioTechnology 7 (4): 212-216.

20. Xiaogang D, Fangqiu Z, Wang $\mathrm{H}$ et al (2013) Bauhinia variegata seedling-specific composite fertilizer. Faming Zhuanli Shenqing.

21. Arain S, Memon N, Rajput M et al. (2012) Physico-chemical characteristics of oil and seed residues of Bauhinia variegata and Bauhinia linnaei. Pakistan Journal of Analytical and Environmental Chemistry 13 (1): 16-21.

22. Sawhney S, Mir M, Amin S (2012) Phytochemical screening and antioxidant properties of Bauhinia variegate. International Journal of Research in Phytochemistry and Pharmacology 2 (1): 21-24

23. Saha S, Subrahmanyam E, Kodangala C et al. (2011) Isolation and characterization of triterpenoids and fatty acid ester of triterpenoid from leaves of Bauhinia variegate. Pharma Chemica 3 (4): 28-37

24. Pandey A, Ojha V, Yadav S, Sahu S et al (2011) Phytochemical evaluation and radical scavenging activity of Bauhinia variegata, Saracaasoka and Terminalia arjuna barks. Research Journal of Phytochemistry 5 (2): 89-97.

25. Shah B, Shah N, Megha R, Dikshit C (2010) Phyto-pharmacological profile of Bauhinia variegata. Pharmacologyonline 2: 829-837.

26. Singh M, Kale R (2010) Abstract A64: Chemopreventive potential of Bauhinia variegata against DMBA-induced skin papillomagenesis in Swiss albino mice. Cancer Prevention Research 3 (1): A64-A64.

27. Rajkapoor B, Murugesh N, Rama DK (2009) Cytotoxic activity of a flavanone from the stem of Bauhinia variegata Linn. Natural Product Research 23 (15): 1384-1389

28. Zhao Y, Cui C, Sun Q (2007) Inhibitory effect on the proliferation of human chronic myeloid leukemia K562 cells 
of bauhinione from Bauhinia variegata. Shenyang Yaoke Daxue Xuebao 24 (2): 109-112

29. Yadava R, Reddy Y (2003) Anti-Inflammatory Activity of a Novel Flavonol Glycoside from the Bauhinia variegata Linn. Natural Product Research 17 (3): 165-169.

30. Widodo N, Kaur K, Shrestha BG et al. (2007) Selective Killing of Cancer Cells by Leaf Extract of Ashwagandha. Identification of a Tumor Inhibitory Factor and The First Molecular Insights to its Effect. Clinical Cancer Research 13 (7): 2298-306.

31. Widodo N, Takagi Y, Shrestha BG et al. (2008) Selective killing of cancer cells by leaf extract of Ashwagandha. Components, activity and pathway analyses. Cancer Letter 262 (1): 37-47. doi: 10.1016/j.canlet.2007.11.037.

32. Bhandari J, Niraula P, Thapa P et al. (2015) Phytochemical screening, antioxidant assay of Juniperus recurva and study of it's in vitro cytotoxicity against breast cancer cell lines. International Journal of Pharma and Bio Sciences 6 (3): (B) 1134-1145.

33. Helfand SL, Werkmeister J, Roder JC (1982) Chemiluminesence response of human natural killer cells: the relationship between target cell binding, chemiluminesence and cytolysis. Journal of Experimental Medicine 156: 492505.

34. Lamichhane B, Adhikari S, Shrestha LP, Shrestha BG (2014) Study of phytochemical, antioxidant, antimicrobial and anticancer activity of Berberis aristata. Journal of Tropical Life Science 4 (1): 1-7.

35. Shrestha P, Bista M, Sharma P et al. (2015) Phytochemical screening, antimicrobial activity and cytotoxicity of Nepalese medicinal plants Swertia chiraita and Dendrobium amoenum. Nepal Journal of Biotechnology 3 (1): 4854 . 